NICE

\section{NICE discrimination}

\section{Rawlins, A Dillon}

\section{The authors refute Harris's criticism of the work of NICE and in turn criticise his description of the institute's position}

$\mathrm{H}$ arris's recent editorial, ${ }^{1}$ It's not NICE to discriminate, is long on both polemic and invective but short on scholarship. He offers nothing to illuminate the debate about allocating health care in circumstances of finite resources; he has no understanding of the quality adjusted life year (QALY) and its use in health economic evaluation; and he makes ill researched, unsubstantiated charges against the institute and its advisory bodies.

\section{ALLOCATING HEALTHCARE RESOURCES}

The British National Health Service (NHS), like every other healthcare system in the world, has finite resources. How the NHS's budget should be most appropriately allocated is a very specific example of the more general problem of distributive justice. ${ }^{2}$

The NHS, with its requirement ${ }^{3}$ to provide all care that is "necessary and appropriate", was founded with an egalitarian purpose. Yet despite its laudable emphasis on fairness, the implementation of the NHS's egalitarian approach remains uncertain. What is necessary? What is appropriate? How should the tensions between the service's egalitarian aspirations, and the need to provide health care from finite resources, be resolved? On what principles should these allocative decisions be made?

Utilitarianism, with its goal to maximise overall good, is another approach. Yet experience with the original Oregon plan demonstrated that, when rigidly applied, it can yield solutions that most find unacceptable-for example, tooth capping taking precedence over emergency appendectomy. ${ }^{4}$ Moreover, some versions of utilitarianism can allow the interests of minorities to be overridden by the majority; and it has next to nothing to offer in eradicating health inequalities.

There is no single, broadly accepted, theory of distributive justice on which either the NHS, or an organisation like the National Institute for Health and Clinical Excellence (NICE), might base its decisions. Harris, himself, while accepting that resources should not be wasted, has offered nothing that approaches a workable solution. In the face of a lack of consensus among moral philosophers, NICE has adopted the principles of procedural justice"accountability for reasonableness" as espoused by Daniels and Sabin. ${ }^{5}$ We are aware that some philosophers believe that it is a betrayal of their discipline to seek pragmatic solutions to these problems ${ }^{6}$; and that moral and political philosophers should devote their time and energy to developing and debating the alternative solutions on offer-or devising new ones. This is fine for those who wish to spend their lives contemplating a paradox that has baffled humankind for over 2000 years; but it is of no help to those of us who live in the real world. At the sharp end of health care, there is an obligation to ensure that NHS resources are used in a manner that takes both clinical and cost effectiveness into account; but that also embodies equity. Some constructive suggestions would be appreciated.

\section{QUALITY ADJUSTED LIFE YEARS}

The preferred approach of NICE, to economic evaluation, is cost utility analysis; ; and the institute uses estimates of QALY as its principal (though not only) measure of health gain. The QALY is simple in concept. It ranks health related quality of life on a scale of zero (dead) to one (full health), and multiplies this by the time (years) during which this improved state of health is enjoyed. If one form of treatment is superior to another, but costs more, the incremental cost effectiveness ratio provides an expression of the additional money required to achieve an improvement in health.

For example, if a particular drug produces an increased QALY of 0.5 compared with current treatment, but at an additional cost of $£ 10,000$ per year, the incremental cost effectiveness ratio will be $£ 20,000$ per QALY (leaving aside complexities such as discounting). Also, provided costs and the health gains are the same, the incremental cost per QALY will be no different for a three year old than for an 83 year old. The QALY is not therefore inherently ageist, although there are two special circumstances when age will come into the reckoning.

First, if there is an age associated change in clinical effectiveness (and hence a change in the QALYs gained), the incremental cost effectiveness ratio will also change. The incremental cost effectiveness of alendronate ${ }^{8}$ - for example, in the secondary treatment of osteoporosis-changes from £32,936/ QALY at age 50 years to $£ 12,191$ at the age of 70 years. This occurs because older patients have a greater risk of complications of osteoporosis and thus benefit more. The institute has documented analogous changes in the cost per QALY, with age, for drugs to prevent or treat influenza, ${ }^{90}$ and with the Cox-2 inhibitors for arthritis. ${ }^{11}$

Second, the elderly might in theory be disadvantaged in the evaluation of an exceptionally expensive procedure, device, or drug (given as a single dose or a short course) whose health gain persists over a long period. A child aged three years would then be likely to enjoy more than 70 years of benefit compared to the additional five years that an 80 year old could expect. We cannot, though, think of a single example of any "one off" life saving treatment costing $£ 150,000$ (for this is what it would have to be if such problem ever arose)!

NICE has been at some pains to explain that it does not differentially value life, across the ages, despite recent media reports to the contrary. Consequently, it does not accept that QALYs should be "weighted" in a manner that would take age into account. ${ }^{12}$ Nevertheless, NICE does consider age where there is no other practical way of identifying the likelihood of clinical effectiveness as in the case of our guidance on in vitro fertilisation (IVF). ${ }^{13}$ As Harris points out, the Institute's guidance recommends that IVF should be provided by the NHS to infertile women aged between 23 and 39 years. The evidence shows that the success rate in older women is very small. Harris, though, suggests that this advice is inappropriate ${ }^{1}$; and that the NHS should offer the chance of IVF to as many women as possible.

This is the point, of course, where Harris leaves the real world and enters a parallel-value and cost free-universe. For if the NHS (or any other healthcare system in the world) were to go along his route, and provide everything anyone wanted, it could consume almost the entirety of a nation's gross domestic product with nothing left for any other form of public (or, for that matter, private) expenditure. 


\section{THE BASIS OF NICE GUIDANCE}

Neither of us develops NICE guidance. It is done by the independent members of our advisory bodies drawn from the NHS, universities, and patients (or patient advocates). They have a free hand, within the framework determined by law (NICE's establishment orders and directions), and by the processes we have developed after exhaustive consultation. And we only pay them expenses.

Harris also stated, ${ }^{1}$ in his editorial, that the preliminary conclusions of the institute's appraisal committee on Alzheimer's drugs was "wickedness or folly or more likely both". His use of invective is contemptible. He is also guilty of misrepresentation. Mr Justice Mars Jones did indeed state:

However gravely ill a man may be...he is entitled in our law to every hour...that God has granted him. That hour or hours may be the most precious and important hours of a man's life. There may be business to transact, gifts to be given, forgiveness to be made, 101 bits of unfinished business, which have to be concluded.

By a curious chain of coincidences one of us (MDR) was present in court, as an expert witness, when these words were uttered, but Harris has taken them totally out of context. They were spoken during Mars Jones's summing up to a jury in the trial of a general practitioner accused of the attempted murder of a man who was mortally ill from lung cancer. The case was about as far removed from ageing or resource allocation as could be imagined.

Despite Harris's assertion to the contrary, the issue of how age might be considered in the allocation of healthcare resources is disputed. ${ }^{12}$ NICE has taken a principled position; and Harris's petulant description of the Institute's stance is unworthy of the editor of a journal that purports to be concerned with ethics and that seeks, we presume, to be ethical in its own editorial conduct.

J Med Ethics 2005;31:683-684.

doi: 10.1136/jme.2005.013813

\section{Authors' affiliations}

M Rawlins, A Dillon, National Institute for Health and Clinical Excellence, MidCity Place, 71 High Holborn, London WC1V 6NA, UK

\section{Correspondence to:}

Professor Sir Michael Rawlins, National Institute for Health and Clinical Excellence, MidCity Place, 71 High Holborn, London WC1V 6NA, UK; michael.rawlins@nice.org.uk

Received 29 July 2005

Accepted for publication 21 August 2005

\section{REFERENCES}

1 Harris J. It's not NICE to discriminate. J Med Ethics 2005;31:373-5.

2 Beauchamp TL, Childress JF. Principles of biomedical ethics. Oxford and New York: Oxford University Press, 2001.
3 National Health Service Act 1977. London: HMSO, 1977.

4 Hadorn DC. Setting health care priorities in Oregon. Cost-effectiveness meets the rule of rescue. JAMA 1991;265:2218-25.

5 Daniels N, Sabin JE. Setting limits fairly: can we learn to share medical resources? Oxford and New York: Oxford University Press, 2002.

6 Kukathas C, Pettit P. Rawls: a theory of justice and its critics. Stanford: Stanford University Press, 1990

7 Rawlins MD, Culyer AJ. National Institute for Clinical Excellence and its value judgements. BMJ 2004:329:224-6.

8 National Institute for Clinical Excellence. Bisphosphonates (alendronate, etidronate, risedronate), selective oestrogen receptor modulators (raloxifene) and parathyroid hormone (teriparatide) for the secondary prevention of osteoporotic fragility fractures in postmenopausal women. Technology appraisal guidance no 87, 2005. http://www.nice.org.uk/ page. aspx?o $=241349$ (accessed 21 Sept 2005).

9 National Institute for Clinical Excellence. Guidance on the use of oseltamivir and amantadine for the prophylaxis of influenzo. Technology appraisal guidance no 67, 2003. http://www.nice.org.uk/pdf/ 67_Flu_prophylaxis_guidance.pdf (accessed 21 Sept 2005).

10 National Institute for Clinical Excellence. Guidance on the use of zanamivir, oseltamivir and amantadine for the treatment of influenza. Technology appraisal guidance no 58, 2005. http://www.nice.org.uk/pdf/ 58_Flu_fullguidance.pdf (accessed 21 Sept 2005).

11 National Institute for Clinical Excellence. Guidance on the use of cyclo-oxygenase (Cox) II selective inhibitors, celecoxib, rofecoxib, meloxicam and etodolac for osteoarthritis and rheumatoid arthritis. Technology appraisal guidance no 27, 2001. hitp://www.nice.org.uk/ page. aspx?o = 241349 (accessed 21 Sept 2005).

12 Sassi F, Archard L, Le Grand J. Equity and the economic evaluation of health care. Health Technol Assess 2001;5:1-138.

13 National Institute for Clinical Excellence. Assessment and treatment for people with fertility problems. Clinical guideline no 11, 2004. http:// www.nice.org.uk/pdf/CG01 lfullguideline.pdf (accessed 21 Sept 2005). 